\title{
Are personal characteristics of massage therapists associated with their clinical, educational, and interpersonal behaviors?
}

\author{
Karen Boulanger, $\mathrm{PhD}, \mathrm{CMT},{ }^{1 *}$ Shelly Campo, $\mathrm{PhD}^{2}$ \\ ${ }^{1}$ Department of Anesthesia, Stanford University School of Medicine, Palo Alto, CA, USA \\ ${ }^{2}$ Department of Community and Behavioral Health, University of Iowa, Iowa City, IA, USA
}

\begin{abstract}
Background: Social Cognitive Theory suggests that characteristics of health professionals, such as their beliefs in the effectiveness of their care, influence their behavior. Studying the characteristics of massage therapists may, therefore, provide insight into their clinical, educational and interpersonal behavior, which ultimately affects their client interactions.

Purpose: To examine the association of three personal factors (outcome expectations, expectancies, and practice experience) of the massage therapist and the practice environment with the frequency of three interventional behaviors (clinical, educational, and interpersonal) using Social Cognitive Theory as a theoretical framework.
\end{abstract}

Methods: A random sample of licensed massage therapists in Iowa completed a mailed questionnaire. Questions included training in massage, use of specific massage techniques and practices, 11 outcome expectations, and 17 different behaviors with their respective expectancies for contributing to favorable client outcomes. Factor analyses were conducted on the behavior and expectancy items. Regression analyses were used to examine the relationship of massage therapist characteristics to the different categories of behavior.

Results: The response rate was $40 \%(N=151)$. The most common techniques employed were Swedish massage, trigger point therapy, and stretching. The most common practices recommended to clients were encouraging water intake, heat application, stretching, stress management, and exercise counseling. Expectancies was the only Social Cognitive Theory variable that significantly predicted the frequency of every category of behavior (clinical, interpersonal, education; all $p$ s $<.01)$. Outcome expectations predicted clinical $(p=.03)$ and educational $(p<.01)$, but not interpersonal behavior. No other associations reached statistical significance.

Conclusions: Massage therapists' belief in massage to enact a favorable change in a client is strongly associated with their clinical, educational, and interpersonal behavior. Massage therapists were optimistic regarding the ability of massage to provide a favorable outcome, especially if the desired outcome was supported by research.

KEY WORDS: Social Cognitive Theory; outcome expectations; expectancies; public health; massage therapy

\section{INTRODUCTION}

The most recent survey of the use of massage therapy was commissioned by the American Massage Therapy Association (AMTA) in 2011. It revealed that $18 \%$ of adults surveyed received a massage, most commonly to manage stress and medical concerns. ${ }^{(1)}$ Although US massage therapists saw an estimated 18 million adults and 700,000 children in $2007,{ }^{(2)}$ few studies have examined the characteristics of massage therapists, ${ }^{(3-5)}$ and none have used a health behavior theory as a framework or evaluated measures of interpersonal behaviors with clients, expectancies, and outcome expectations of massage therapy.

Researchers have found that the interpersonal behaviors of medical providers are related to patient outcomes; $;^{(6-8)}$ these same behaviors have also been hypothesized to influence the outcomes of those receiving complementary and alternative medicine. ${ }^{(9)}$ People seek massage therapy for symptom reduction, ${ }^{(10)}$ requiring massage therapists to be better equipped with interpersonal communication skills to facilitate understanding of the client's condition. In addition, a research review has shown that patients whose health care providers display enthusiasm (positive expectations) toward treatment have greater symptom relief. ${ }^{(11)}$ Although the potential for massage therapists' personal characteristics and expectations to partially explain the effects of massage has been suggested, ${ }^{(12)}$ they remain unexamined. Therefore, the purpose of this study was to examine the association of three personal factors (outcome expectations, expectancies, and practice experience) of the massage therapist and the practice environment with the frequency of three interventional behaviors (clinical, educational, and interpersonal) using Social Cognitive Theory as a theoretical framework. 
Social Cognitive Theory serves as the foundation for this study as it provides a framework for how a person's personal characteristics, behavior, and environment interact and influence each other. ${ }^{(13)}$ The theory includes several constructs that are used to help understand, predict, and/or change health-related behavior. Examples of personal characteristics that are hypothesized to influence behavior are outcome expectations and expectancies. Outcome expectations are the anticipated consequences of a behavior. They are learned from previous experience, or from observing or hearing about another's experience, and from physiological arousal. ${ }^{(13)}$ In other words, we learn in a variety of ways that certain behaviors have certain consequences and we expect these same consequences to occur when we behave similarly in analogous situations. An expectancy is the value we place on a particular outcome. ${ }^{(14)}$ Consequences of behavior that we perceive as personally meaningful and positive will motivate us to engage in or repeat that related behavior. In this way, expectations and expectancies guide our behavior.

Outcome expectations are often measured in evaluation and research which uses Social Cognitive Theory as a framework. ${ }^{(15)}$ Applications include designing interventions to increase outcome expectations related to physical activity ${ }^{(16-17)}$ and home exercise adherence. (18) Other studies have applied outcome expectation and expectancy constructs to improve participation in longitudinal studies ${ }^{(19)}$ and exercise adoption among an at-risk population. ${ }^{(20)}$ In addition, reviews indicate that outcome expectation variables have been used to explain clinical behaviors in physicians, nurses, pharmacists, and psychologists, ${ }^{(21)}$ and in physicians' use of clinical practice guidelines. ${ }^{(2)}$ This study uses Social Cognitive Theory as a framework to examine the influence that personal characteristics of massage therapists (their outcome expectations, expectancies, and experience) and their practice environment have on a variety of behaviors that ultimately impact the health outcomes of their clients. ${ }^{(23)}$ In this study, outcome expectations are the expectations held by massage therapists regarding several different potential benefits of massage therapy (e.g., decreased pain and improved mood). Outcome expectations are shaped by past experiences with related situations and from watching or hearing about others' experiences in related situations. ${ }^{(14)}$ Outcome expectations, a Social Cognitive Theory construct, were selected because they are likely to be viewed as incentives for massage therapists to act in ways that will produce positive outcomes and thus influence their behavior. ${ }^{(24)}$ For example, if a massage therapist expects that massage will relax her client, then the massage therapist will engage in behavior (e.g., act like a friend and give ideas about how to manage stress) that makes the interventional goal (e.g., relaxation) more probable.

In this study, expectancies are defined as the importance that massage therapists place on various behaviors in order to achieve intended results. For example, if a massage therapist believes that it is important to engage in various behaviors (e.g., act like a friend, and give ideas about how to manage stress) in order for her client to relax, then the massage therapist is more likely to engage in those behaviors. This construct was chosen as Social Cognitive Theory asserts that, along with outcome expectations, expectancies also predict behavior. Whereas an outcomes expectation tells us, for example, that a massage therapist believes that massage will help a client relax, an expectancy tells us that the ability of massage to help a client relax is valued by the therapist.

The final personal factor being examined in this study that may influence the behavior of massage therapists is their practice experience (i.e., the number of years since they graduated from their initial training program). According to Social Cognitive Theory, massage therapists are more likely to engage in behaviors that they have appropriate knowledge of and skills to perform.

The environment relevant to this study is the practice environment, whether the massage therapist practices alone or with others. Although some massage therapists prefer to work alone, others work in a variety of settings with a variety of other professionals. According to Social Cognitive Theory, the presence of peers in the working environment may be a source of social support for engaging in related behaviors and, therefore, increase the frequency of their occurrence.

In this study, a broad range of massage therapists' behavior is being examined in order to represent the clinical, educational, and interpersonal nature of their work. For example, in addition to assessing muscles, massage therapists often educate their clients regarding the benefits of massage and discuss clients' concerns with them. As stated earlier, according to Social Cognitive Theory, outcome expectations, expectancies, practice experience, and environment influence behavior. ${ }^{(13)}$ The theory-driven research question in this study is: Are personal factors of the massage therapist (outcome expectations, expectancies, and practice experience) and the practice environment associated with the frequency of various behaviors?

\section{METHODS}

\section{Participants}

This study included a cross-sectional sample of licensed massage therapists in Iowa. Contact information for these therapists was obtained through the Iowa Department of Public Health website. ${ }^{(25)}$ Massage therapists in Iowa were chosen for two primary reasons. First, previous studies have not explored massage therapy practice in the Midwest. Second, Iowa has a 20 -year history of requiring licensure in order to practice massage therapy in the state, indicating 
some degree of basic equivalency in training, knowledge, skills, and continuing education. Massage therapists were eligible for this study if they listed an Iowa address, were not under disciplinary action, and were currently in practice. In September 2008, 2,254 massage therapists were available for sampling. Of these, 400 were randomly selected (using a random numbers table) to receive a mailed survey.

\section{Measures: lowa Massage Therapist Survey}

\section{Participant characteristics}

The four-page survey began with questions regarding massage therapists' gender, age, and training. It proceeded with questions regarding practice setting, client workload, and other employment. The final item asked respondents to report the use of seven techniques (e.g., Swedish massage and trigger point therapy) and seven practices (e.g., stretching recommendations and stress management), with three response options (never use the technique/practice, use it with some clients, or use it with majority of clients).

\section{Outcome expectations}

Massage therapists were asked to rate the degree to which they agreed or disagreed with 11 statements regarding the outcomes of massage therapy on a seven-option Likert scale ("strongly agree/disagree, slightly agree/disagree, neither agree nor disagree"). One example of a statement is, "Massage therapy will decrease the amount of pain my clients have." The outcomes list was generated from prior research that supported the relationship between massage therapy and improvements in pain, concentration, stress, sleep, immunity, mood, and blood pressure. ${ }^{(12,26-30)}$

\section{Behavior}

Massage therapists were asked to rate how often they engage in 17 behaviors with their clients using five frequency responses (almost always, often, sometimes, rarely, and never). For example, "As a massage therapist, I assess my clients' muscles to understand their condition." The 17 behaviors that were included are complementary to items that were written for a scale measuring client expectations of massage. ${ }^{(30)}$ For example, if the client version read, "I expect that my massage therapist may assess my muscles to understand my condition," then the complementary item on the survey in this study was, "As a massage therapist, I assess my clients' muscles to understand their condition."

\section{Expectancies}

Massage therapists were asked to assess how important the 17 above-noted behaviors are to obtain good massage therapy outcomes. For example, "To achieve excellent results from massage, it is valuable for me to assess my clients' muscles to understand their condition."

\section{Procedure}

In October 2008, surveys were mailed to prospective participants with an invitation letter signed by an Iowa-licensed massage therapist/researcher (KB). A self-addressed stamped return envelope was also included. In a Cochrane Collaboration review, these procedures were found to maximize response rates. ${ }^{(31)}$ Three weeks after the initial mailing, a computer-generated random sample of 50 massage therapists who did not respond to the initial survey was contacted by telephone to remind them of their invitation to participate in the survey. The surveys took approximately 5-10 minutes to complete. All procedures were approved by the University's institutional review board, including waiver of informed consent. An early version of the survey was pilot tested by 25 massage therapists for time requirements and reading comprehension, and then revised. The final survey was pilot tested by five massage therapists.

\section{Analysis}

Descriptive statistics, exploratory factor analyses, and regression analyses were conducted using the Statistical Package for the Social Sciences (SPSS) 17.0. Six items were removed from inclusion in the potential expectancy and behavior subscales due to low variability (i.e., respondents rated the item similarly). Principal component analyses with varimax rotation were conducted on the expectancy and behavior items. Three categories of expectancy and behavior emerged from the principal component analysis: clinical, interpersonal, and educational (see Tables 1 and 2). One item (put my clients in a better mood) did not load on any factor and was dropped from further analyses. Internal consistency was adequate (alphas ranged from .61 to .77). ${ }^{(32)}$

To examine the relationships of the Social Cognitive Theory variables, three separate regression models were tested using each sum of responses to the clinical, educational, and interpersonal behaviors as the dependent variable. The following independent variables were included for each regression model: the sums of the responses to the outcome expectations question, the sums of the categories of expectancy items (clinical, educational, and interpersonal), number of years since initial completion of massage training, and a dummy variable for whether or not the massage therapist practices with others. The significance level was set at 0.05 . See Figure 1 for an example of how the variables in the clinical behavior model were tested. Educational and interpersonal behaviors were tested similarly.

The age, gender, and year of licensure for every massage therapist who is licensed in Iowa are available to the public through the Iowa Department of Public Health website. To determine whether there were significant differences between responders and 
TABLE 1. Expectancies of a Random Sample of Massage Therapists in Iowa, b

\begin{tabular}{|c|c|c|c|c|}
\hline To achieve excellent results from massage, it is valuable for me to: & Mean & $S D$ & Factor Loading & Cronbach's $\alpha$ \\
\hline Clinical & & & & .77 \\
\hline Assess my clients' muscles to understand their condition & 6.6 & 0.8 & .78 & \\
\hline Teach my clients how to prevent their condition from becoming worse & 6.4 & 0.9 & .81 & \\
\hline Explain to my clients the cause of their muscular tension & 6.0 & 1.0 & .81 & \\
\hline Provide my clients with information regarding their condition & 5.8 & 1.2 & .56 & \\
\hline Educational & & & & .61 \\
\hline Educate my clients on the benefits of massage therapy & 6.5 & 0.7 & .68 & \\
\hline Give my clients ideas on how to manage their stress & 5.8 & 1.1 & .69 & \\
\hline Talk to my clients about eating well (nutrition) & 5.3 & 1.3 & .80 & \\
\hline Interpersonal & & & & .76 \\
\hline Act like a friend to my clients & 4.2 & 1.7 & .80 & \\
\hline Discuss my clients' personal problems with them & 3.6 & 1.7 & .79 & \\
\hline Share personal aspects of my life with my clients & 2.7 & 1.5 & .84 & \\
\hline \multicolumn{5}{|l|}{ Items not included in the exploratory factor analysis } \\
\hline Respect my clients' modesty. & 6.9 & 0.4 & & \\
\hline Tailor my massage approach to suit my clients' individual needs & 6.9 & 0.3 & & \\
\hline Be a person that my clients can trust & 6.8 & 0.5 & & \\
\hline Help my clients feel relaxed & 6.8 & 0.5 & & \\
\hline Have exceptional massage skills & 6.8 & 0.6 & & \\
\hline Show concern for my clients & 6.7 & 0.7 & & \\
\hline Put my clients in a better mood & 6.0 & 1.1 & & \\
\hline
\end{tabular}

${ }^{\mathrm{a}} \mathrm{n}=151$.

${ }^{\mathrm{b}}$ All variables are on a Likert scale where $7=$ strongly agree and $1=$ strongly disagree.

TABLE 2. Frequency of a Random Sample of Iowa Massage Therapists Behaviors ${ }^{\mathrm{a}, \mathrm{b}}$

\begin{tabular}{|c|c|c|c|c|}
\hline As a massage therapist, $I$ & Mean & $S D$ & Factor Loading & Cronbach's $\alpha$ \\
\hline Clinical & & & & .72 \\
\hline Assess my clients' muscles to understand their condition & 4.6 & 0.7 & .73 & \\
\hline Teach my clients how to prevent their condition from becoming worse & 4.3 & 0.8 & .73 & \\
\hline Explain to my clients the cause of their muscular tension & 4.0 & 0.8 & .76 & \\
\hline Provide my clients with information regarding their condition & 3.9 & 1.1 & .55 & \\
\hline Educational & & & & .61 \\
\hline Educate my clients on the benefits of massage therapy & 4.5 & 0.6 & .70 & \\
\hline Give my clients ideas on how to manage their stress & 3.7 & 0.9 & .78 & \\
\hline Talk to my clients about eating well (nutrition) & 3.5 & 1.0 & .72 & \\
\hline Interpersonal & & & & .64 \\
\hline Act like a friend to my clients & 3.5 & 1.1 & .72 & \\
\hline Share personal aspects of my life with my clients & 2.6 & 0.9 & .77 & \\
\hline Discuss my clients' personal problems with them & 2.6 & 0.9 & .73 & \\
\hline \multicolumn{5}{|l|}{ Items not included in the exploratory factor analysis } \\
\hline Am a person that my clients can trust & 5.0 & 0.1 & & \\
\hline Respect my clients' modesty & 5.0 & 0.1 & & \\
\hline Help my clients feel relaxed & 4.9 & 0.3 & & \\
\hline Tailor my massage approach to suit my clients' individual needs & 4.9 & 0.3 & & \\
\hline Show concern for my clients & 4.9 & 0.4 & & \\
\hline Have exceptional massage skills & 4.6 & 0.6 & & \\
\hline Put my clients in a better mood & 4.4 & 0.6 & & \\
\hline
\end{tabular}

${ }^{\mathrm{a}} \mathrm{n}=151$

${ }^{\mathrm{b}}$ All variables are on a frequency scale where $5=$ almost always and $1=$ never. 


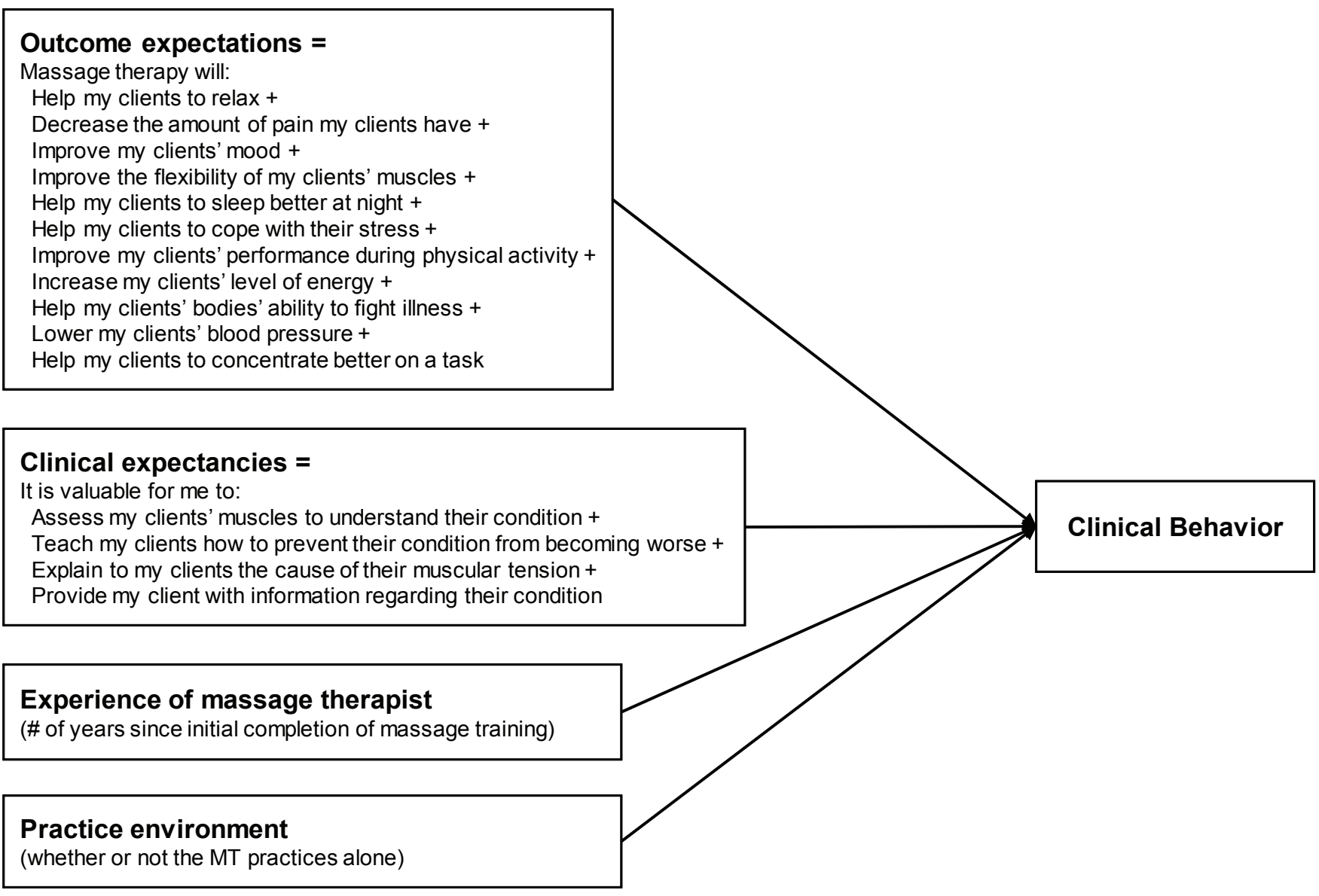

FIGURE 1. Model testing the influence of Social Cognitive Theory variables on the clinical behavior of massage therapists.

nonresponders at the time the sample was drawn, Chi-square goodness-of-fit analysis was used to test for differences in gender and independent $t$ tests were used to test for differences in age and years since licensure.

\section{RESULTS}

\section{Response Rate}

Of the 400 surveys that were mailed out, 143 were returned completed, six were returned as undeliverable, five were forwarded to massage therapists that had moved out of state, five were received by massage therapists that reported that they were no longer in practice, and 14 were returned blank. Of the 50 randomly selected nonresponders, eight returned a completed survey, eight phone numbers were no longer in service, 24 were left a voicemail message, two had retired from practice, and eight indicated that they would return the survey, but it was never received. In total, 151 were returned completed, 227 surveys were not returned, and four surveys were removed due to incomplete responses resulting in a $40 \%$ response rate $(151 / 382)$.

\section{Participant Characteristics}

The mean hours of initial training completed was 688 (range $=500-1500)$ and the mean years since basic training was completed was 6.2 (range $=0.5-22$ ). Nearly half of the massage therapists practiced alone $(45.7 \%)$, while $15.9 \%$ practiced with a chiropractor, $14.6 \%$ practiced in a salon or spa, $12.6 \%$ practiced with other massage therapists, and $12 \%$ worked in other practice settings. There was a large range (1-60) in the number of hours spent with clients each week; the average was 15.8 hours. An average of 14 clients (range $=1-45$ ) were cared for in a typical week. A little more than half $(53.6 \%)$ of respondents were also employed in a job other than as a massage therapist.

The massage techniques most commonly used by therapists were Swedish massage (92.7\%), trigger point therapy $(53.0 \%)$, and stretching $(46.4 \%)$ (Table 3). Techniques used less regularly were Reiki or therapeutic touch and craniosacral therapy. The most common practices were encouraging water intake, heat application, stretching recommendations, stress management, and exercise counseling. Practices used less regularly were aromatherapy and cold application. 
TABle 3. A Random Sample of Massage Therapists' in Iowa Percent Use of Techniques and Practice with Clients ${ }^{\mathrm{a}}$

\begin{tabular}{|c|c|c|c|}
\hline & $\begin{array}{c}\text { Never } \\
\text { Use }\end{array}$ & $\begin{array}{c}\text { Use with } \\
\text { Some } \\
(<50 \%)\end{array}$ & $\begin{array}{c}\text { Use with } \\
\text { Most } \\
(50 \%+)\end{array}$ \\
\hline \multicolumn{4}{|l|}{ Technique } \\
\hline Swedish massage & $2.0 \%$ & $5.3 \%$ & $92.7 \%$ \\
\hline Trigger Point therapy & 9.3 & 97.1 & 53.0 \\
\hline Stretching during session & 9.3 & 44.4 & 46.4 \\
\hline Reflexology & 21.9 & 49.7 & 28.5 \\
\hline Neuromuscular therapy & 34.5 & 38.5 & 27.0 \\
\hline Reiki or therapeutic touch & 60.3 & 23.8 & 15.9 \\
\hline Craniosacral therapy & 57.0 & 28.9 & 14.1 \\
\hline \multicolumn{4}{|l|}{ Practice } \\
\hline $\begin{array}{l}\text { Encourage increased water } \\
\text { intake }\end{array}$ & $0.7 \%$ & $5.3 \%$ & $94.0 \%$ \\
\hline $\begin{array}{l}\text { Heat application (hot pack, } \\
\text { heating pad) }\end{array}$ & 8.7 & 43.3 & 48.0 \\
\hline $\begin{array}{l}\text { Stretching recommendations for } \\
\text { home/work }\end{array}$ & 4.0 & 51.7 & 44.3 \\
\hline Stress management & 15.9 & 42.8 & 41.4 \\
\hline $\begin{array}{l}\text { Exercise counseling (for general } \\
\text { health) }\end{array}$ & 13.5 & 55.4 & 31.1 \\
\hline Aromatherapy & 31.3 & 42.7 & 26.0 \\
\hline Ice or cold application & 34.4 & 53.0 & 12.6 \\
\hline
\end{tabular}

${ }^{a} \mathrm{n}=151$.

A comparison of respondents to the survey to nonrespondents was conducted. No difference in gender, age, or years since licensure was found. Specifically, $89 \%$ of the responders were female compared to $86 \%$ of nonresponders; $\left(\chi^{2}=2.16, \mathrm{df}=1, p=.15\right)$; the mean age of respondents was 40.7 years compared to 39.8 for nonresponders $(t=-.67, \mathrm{df}=381, p=.50)$; average years since licensure for both respondents and nonrespondents were 6.2.

\section{Outcome Expectations, Expectancies, and Behavior}

In general, the massage therapists had high levels of expectations for positive massage outcomes, especially regarding relaxation, pain reduction, improving mood, and increasing muscle flexibility. Respondents had the lowest expectations for improving concentration and lowering blood pressure (Table 4). Massage therapists in this sample tended to rate the importance of clinical and educational behaviors higher than the importance of interpersonal behaviors to achieve favorable results from massage (Table 1). Parallel to the expectancies, the most prevalent behaviors were more clinical in nature: being trustworthy, showing concern, respecting modesty, tailoring the session, and helping clients to relax. There was more variability in interpersonal behaviors such as acting like
TABLE 4. Outcome Expectations of a Random Sample of Massage Therapists in Iowa ${ }^{\mathrm{a}, \mathrm{b}}$

\begin{tabular}{lcc}
\hline \multicolumn{1}{c}{ Massage therapy will: } & Mean & SD \\
\hline Help my clients to relax & 6.8 & 0.4 \\
Decrease the amount of pain my clients have & 6.6 & 0.6 \\
Improve my clients' mood & 6.6 & 0.6 \\
Improve the flexibility of my clients' muscles & 6.5 & 0.7 \\
Help my clients to sleep better at night & 6.5 & 0.7 \\
Help my clients to cope with their stress & 6.4 & 0.7 \\
Improve my clients' performance during & 6.2 & 0.8 \\
physical activity & & \\
Increase my clients' level of energy & 6.2 & 0.8 \\
Help my clients' bodies' ability to fight illness & 6.1 & 0.9 \\
Lower my clients' blood pressure & 5.9 & 1.1 \\
Help my clients to concentrate better on a task & 5.7 & 1.1 \\
\hline
\end{tabular}

${ }^{\mathrm{a}} \mathrm{n}=151$.

${ }^{\mathrm{b}}$ All variables are on a Likert scale where $7=$ strongly agree and $1=$ strongly disagree.

a friend to clients, as well as educational behaviors such as discussing nutrition (Table 2).

\section{Predicting Behavior}

Using regression analysis, expectancies was the only Social Cognitive Theory variable that significantly predicted the frequency of every category of behavior (clinical, $p<.01$; interpersonal, $p<.01$; educational, $p<.01$ ) (see Table 5). In other words, if the massage therapist expected a behavior would lead to good results, he/she was more likely to engage in that respective behavior more frequently. Outcome expectations predicted clinical $(p=.03)$ and educational $(p<.01)$ behavior, but not interpersonal behavior. Number of years since completion of initial massage training predicted the frequency of clinical behavior $(p=.01)$ where more experienced massage therapists engaged in clinical behaviors more often. The social environment (whether or not the massage therapist practiced with others) did not explain any variance in any category of behavior ( $p$-values ranged from 0.29 to 0.54 ).

\section{DISCUSSION}

Outcome expectations and expectancies predicted the frequency of clinical and educational behaviors. In other words, massage therapists with favorable expectations regarding massage were likely to engage in clinical and educational behaviors more often. Similarly, massage therapists who believed that clinical and educational behaviors were important to obtain favorable results for their clients were likely to engage in those behaviors more often. These findings 


\begin{tabular}{|c|c|c|c|c|c|c|c|c|c|}
\hline \multirow[b]{3}{*}{ Independent Variable } & \multicolumn{9}{|c|}{ Dependent Variable } \\
\hline & \multicolumn{3}{|c|}{$\begin{array}{c}\text { Model 1: } \\
\text { Clinical Behaviors }\end{array}$} & \multicolumn{3}{|c|}{$\begin{array}{c}\text { Model 2: } \\
\text { Educational Behaviors }\end{array}$} & \multicolumn{3}{|c|}{$\begin{array}{c}\text { Model 3: } \\
\text { Interpersonal Behaviors }\end{array}$} \\
\hline & $\beta$ & $S E B$ & $\beta$ & $B$ & $S E B$ & $\beta$ & $B$ & $S E B$ & $\beta$ \\
\hline Outcome expectations & 0.05 & 0.02 & $0.12^{\mathrm{b}}$ & 0.06 & 0.02 & $0.18^{\mathrm{b}}$ & 0.02 & 0.02 & 0.04 \\
\hline Expectancies & 0.59 & 0.04 & $0.71^{\mathrm{b}}$ & 0.53 & 0.05 & $0.65^{\mathrm{b}}$ & 0.40 & 0.03 & $0.73^{b}$ \\
\hline Experience & 0.07 & 0.03 & $0.14^{\mathrm{b}}$ & 0.03 & 0.02 & 0.09 & 0.05 & 0.02 & 0.12 \\
\hline \multirow[t]{2}{*}{ Practices with others } & -0.17 & 0.28 & -0.03 & -0.20 & 0.22 & -0.05 & 0.27 & 0.25 & 0.06 \\
\hline & \multicolumn{3}{|c|}{$\mathrm{R}^{2}=.58$} & \multicolumn{3}{|c|}{$\mathrm{R}^{2}=.57$} & \multicolumn{3}{|c|}{$\mathrm{R}^{2}=.56$} \\
\hline
\end{tabular}

${ }^{\mathrm{a}} \mathrm{n}=151$

$\mathrm{b}_{\mathrm{p}}<.05$.

are consistent with other studies which used Social Cognitive Theory to understand the behavior of health care providers. For example, outcome expectancies predicted the clinical behavior (placing fissure sealants) of dentists, ${ }^{(33)}$ and outcome expectations predicted the educational behavior (recommending smoking cessation services) of physicians. (34)

Furthermore, interpersonal expectancies, but not outcome expectations, predicted interpersonal behavior. Consistent with Social Cognitive Theory, massage therapists who placed a higher value on interpersonal behaviors were more likely to engage in interpersonal behaviors more often. Furthermore, the number of years since completion of initial massage training approached significance in predicting interpersonal behavior $(p=.056)$. Massage therapists who value the more interpersonal nature of their work may stay in practice longer or massage therapists could become increasingly confident as they interact with more clients over time. Of the interpersonal behaviors, showing concern for clients and being a person whom clients can trust were rated as highly valued, and nearly all of the massage therapists reported that they engaged in these behaviors often or almost always. The items for which variation was observed were related to being like a friend to clients, sharing personal aspects of their life with clients, and discussing clients' personal problems. The finding that outcome expectations did not predict interpersonal behavior could be a result of low self-confidence in their communication skills, a perception that interpersonal communication is not the main goal of the session, a perception that talking during massage interferes with relaxation, or a perception that discussing personal issues (vs. clinical issues) is outside the scope of massage therapy practice.

The remaining Social Cognitive Theory variable, the practice environment, was not associated with any category of massage therapist behavior. The exact reason why massage therapist behavior is not related to whether he/she practices alone vs. with others is unknown. It is possible that massage therapists have other social supports in place that influence their behavior that were not measured in this study. It should also be recognized that the low variance in the frequency of the behaviors studied may have affected the ability of the regression analysis to explain relationships with the experience level of the massage therapist and whether or not the massage therapist practiced with others.

The data from this study provided a very relevant and previously undocumented finding: massage therapists had high expectations regarding the benefits of massage. Expectations were highest for the outcomes in which there is the most scientifically supported evidence for effectiveness (i.e., decreased anxiety, pain, and depression), which could help to explain the nonspecific effects associated with massage. ${ }^{(35)}$ It is possible that massage therapists are transferring their confidence in the benefits of massage to their clients. Medical professionals who report high outcome expectations have better health outcomes for their patients. ${ }^{(11,36-37)}$ Future research investigating the relationship of massage therapists' expectations to their clients' health outcomes is warranted.

One limitation is that this was a cross-sectional survey; the relationship between outcome expectations, expectancies, and behavior may be better assessed through a longitudinal study, as a threshold (e.g., number of years in practice) may be detected that better explains clinical behaviors. In addition, this survey included self-reported behavior; direct observation of massage therapist practice behaviors may have provided a more accurate depiction of techniques and practices used. ${ }^{(22)}$

The response rate from massage therapists was typical of surveys that do not provide incentives; thus, we believe the results are representative of the massage therapists in Iowa. ${ }^{(31)}$ Moreover, the sample of massage therapists who responded was similar to 
those who did not respond in terms of gender, age, and years since initial licensure. Although the majority of respondents were women, this is reflective of the population of massage therapists in Iowa (i.e., both the sample and the population were $89 \%$ female). ${ }^{(38)}$ In addition, the characteristics of massage therapists in this study were consistent with previous state-based studies regarding gender, ${ }^{(3-4)}$ age, ${ }^{(3-4)}$ working in a variety of settings, ${ }^{(3-4)}$ working part time, ${ }^{(3-4)}$ median hours of initial training, ${ }^{(4)}$ years in practice ${ }^{(4)}$ most common type of massage therapy used, ${ }^{(3-4)}$ and respondents' tendency to provide self-care recommendations such as increased water intake and exercise. (5) Future studies should consider using a national sample to obtain a broader picture of the characteristics, expectations, and behavior of massage therapists.

The massage therapists in this study were acting as health promoters in areas related to diet, stress management, and exercise counseling for general health. For example, they believed it was valuable to talk to their clients about eating well, and half reported doing so often or almost always. Coursework on nutrition is not required for national certification exams or for massage school accreditation, so it is unclear whether nutritional information is learned through formal education or practical experience. Nonetheless, future research should explore the influence of massage therapists providing general (not prescriptive) nutritional information on client health.

In a study of preventive screening of women who used Complementary and Alternative Medicine (CAM) providers, the authors reported that women who saw massage therapists were more likely to get mammograms and Pap testing for cancer screening. (39) They concluded that when women use CAM providers as an alternative to (vs. along with) their medical doctor, the recommendations given by that provider may be their main source of encouragement to seek out preventive screening. Future research should investigate the frequency with which massage therapists encourage routine preventive screenings such as mammograms, Pap tests, and colonoscopies. Research is also needed to determine whether acknowledging and fostering the participation of massage therapists in the public health workforce increases positive health outcomes. ${ }^{(40)}$ This research would be well-guided by Social Cognitive Theory, especially the construct of self-efficacy. If massage therapists have high selfefficacy (confidence in their ability to perform specific behaviors), this likely affects their behavior and hence their clients' health outcomes.

In their most recent strategic plan, the National Center for Complementary and Alternative Medicine ${ }^{(41)}$ identified the role of CAM providers as supporters and promoters of healthy behavior as a research priority. At the same time, some massage therapists are exploring opportunities to become more active public health partners, for example by providing panels which discuss public health at massage therapy research conferences. ${ }^{(42)}$ In addition, the ATMA ${ }^{(1)}$ reported that $29 \%$ of members work in a health care setting. Research examining the role of massage therapists as partners with public health initiatives seems timely.

\section{CONCLUSION}

Massage therapists in this study, like massage therapists in other studies, used a variety of techniques and practices to address their clients' concerns. In addition, they were optimistic regarding the ability of massage to provide good outcomes, especially those benefits that were supported by research. This was the first study to apply Social Cognitive Theory to massage therapy research, providing insight into the expectations, values, and behaviors of a sample of massage therapists. Mainly, massage therapists engage in behaviors more frequently if they believe that the behaviors will influence better health outcomes for their clients. These findings are useful for future theory-based research efforts, especially those that seek to understand or change the behavior of massage therapists.

\section{CONFLICT OF INTEREST NOTIFICATION}

The authors declare there are no conflicts of interest.

\section{COPYRIGHT}

Published under the CreativeCommons AttributionNonCommercial-NoDerivs 3.0 License.

\section{REFERENCES}

1. American Massage Therapy Association. 2013 Massage Therapy Industry Fact Sheet. Retrieved February 22, 2012 from: http://www.amtamassage.org/infocenter/economic_industryfact-sheet.html

2. Barnes PM, Bloom B, Nahin RL. Complementary and alternative medicine use among adults and children: United States, 2007. National Health Statistics Report, no 12. Hyattsville, MD: National Center for Health Statistics; 2008.

3. Lee AC, Kemper KJ. Practice patterns of massage therapists. J Altern Complement Med. 2000;6(6):527-529.

4. Cherkin DC, Deyo RA, Sherman KJ, Hart LG, Street JH, Hrbek A, et al. Characteristics of licensed acupuncturists, chiropractors, massage therapists, and naturopathic physicians. $\mathrm{J} \mathrm{Am}$ Board Fam Med. 2002;15(5):378-390.

5. Sherman KJ, Cherkin DC, Kahn J, Erro J, Hrbek A, Deyo RA, et al. A survey of training and practice patterns of massage therapists in two US states. BMC Complement Altern Med. 2005;5:13. Available from: www.biomedcentral.com/1472$6882 / 5 / 13$ 
6. Frantsve LM, Kerns RD. Patient-provider interactions in the management of chronic pain: current findings within the context of shared medical decision making. Pain Med. 2007;8(1):25-35.

7. Heritage J, Maynard D. Problems and prospects in the study of physician-patient interaction: 30 years of research. Annu Rev Sociol. 2006;32:351-374.

8. Stewart MA. Effective physician-patient communication and health outcomes: a review. Can Med Assoc J. 1995;152(9):1423-1433.

9. Long AF. Outcome measurement in complementary and alternative medicine: unpicking the effects. J Altern Complement Med. 2002;8(6):777-786.

10. Hawk C, Ndetan H, Evans MW. Potential role of complementary and alternative health care providers in chronic disease prevention and health promotion: an analysis of National Health Interview Survey data. Prev Med. 2012;54(1):18-22.

11. Crow R, Gage H, Hampson S, Hart J, Kimber A, Thomas H. The role of expectancies in the placebo effect and their use in the delivery of health care: a systematic review. Health Technol Assess. 1999;3(3):1-96.

12. Moyer CA, Rounds J, Hannum JW. A meta-analysis of massage therapy research. Psychol Bull. 2004;130(1):3-18.

13. Bandura A. Social Foundations of Thought and Action: a Social Cognitive Theory. Englewood Cliffs, NJ: Prentice Hall; 1986.

14. Baranowski T, Perry CL, Parcel GS. How individuals, environments, and health behavior interact: social cognitive theory. p. 165-184. In: Glanz K, Rimer BK, Lewis FM, editors. Health Behavior and Health Education: Theory, Research, and Practice, 3rd edition. San Francisco, CA: Jossey-Bass; 2002.

15. Bandura AJ. Self-efficacy: the exercise of control. New York: W.H. Freeman and Company; 1997.

16. Basen-Engquist K, Carmack CL, Perkins H, Hughes D, Serice $\mathrm{S}$, Scrugggs $\mathrm{S}$, et al. Design of the steps to health study of physical activity in survivors of endometrial cancer: testing a social cognitive theory model. Psychol Sport Exerc. 2011;12(1):27-35.

17. Contento IR, Koch PA, Lee H, Calabrese-Barton A. Adolescents demonstrate improvement in obesity risk behaviors after completion of Choice, Control \&Change, a curriculum addressing personal agency and autonomous motivation. Am Diebetic Assoc. 2010;110(12):1830-1839.

18. Sirur R, Richardson J, Wishart L, Hanna S. The role of theory in increasing adherence to prescribed practice. Physiother Can. 2009;61(2):68-77.

19. Sinicrope PS, Patten CA, Bonnema SM, Almquist JR, Smith CM, Bebbe TJ, et al. Healthy women's motivators and barriers to participation in a breast cancer cohort study: a qualitative review. Ann Epidemiol. 2009;19(7):484-493.

20. Hays LM, Pressler SJ, Damush, TM, Rawl SM, Clark DO. Exercise adoption among older, low-income women at risk for cardiovascular disease. Public Health Nurs. 2010;27(1):79-88.

21. Godin G, Belanger-Gravel A, Eccles M, Grimshaw J. Healthcare professionals' intentions and behaviours: a systematic review of studies based on social cognitive theories. Implement Sci. 2008;3:36.

22. Cabana MD, Rand CS, Powe NR, Wu AW, Wilson MH, Abboud PC, et al. Why don't physicians follow clinical practice guidelines? A framework for improvement. JAMA. 1999;282(15):1458-1465.
23. Fischer MJ, Ahya SN, Gordon EJ. Interventions to reduce late referrals to nephrologists. Am J Nephrol. 2011;33(1):60-69.

24. Bandura AJ. Health promotion from the perspective of social cognitive theory. Psychol Health. 1998;13(4):623-649.

25. Iowa Department of Public Health. http://www.idph.state.ia.us/

26. Buttagat V, Eungpinichpong W, Chatchawan U, Kharmwan S. The immediate effects of traditional Thai massage on heart rate variability and stress-related parameters in patients with back pain associated with myofascial trigger points. J Bodyw Mov Ther. 2011;15(1):15-23.

27. Castro-Sanchez AM, Mataran-Penarrocha GA, Granero-Molina J, Aguilera-Manrique G, Quesada-Rubio JM, Moreno-Lorenzo C. Benefits of massage-myofascial release therapy on pain, anxiety, quality of sleep, depression, and quality of life in patients with fibromyalgia. eCAM. 2011.

28. Nerbass FB, Feltrim MIZ, de Souza SA, Ykeda DS, Lorenzi-Filho F. Effects of massage therapy on sleep quality after coronary artery bypass graft surgery. Clinics. 2010;65(11):1105-1110.

29. Rapaport MH, Schettler P, Bresee C. A preliminary study of the effects of a single session of Swedish massage on hypothalamicpituitary-adrenal and immune function in normal individuals. J Altern Complement Med. 2010;16(10):1079-1088.

30. Boulanger KT, Campo S, Glanville J, Lowe JB, Yang JY. The development and validation of the client expectations of massage scale. Int $J$ Ther Massage Bodywork. 2012;5(3):1-15.

31. Edwards P, Roberts I, Clarke M, DiGuiseppi C, Pratap $\mathrm{S}$, Wentz R, et al. Methods to increase response rates to postal questionnaires (review). Cochrane Database Syst Rev. 2007;2:1-236.

32. Clark LA, Watson D. Constructing validity: basic issues in objective scale development. Psychol Assess. 1995;7(3):309-319.

33. Bonetti D, Johnston M, Clarkson J, Turner S. Applying multiple models to predict clinicians' behavioural intention and objective behaviour when managing children's teeth. Psychol Health. 2009;24(7):843-860.

34. Vogt F, Hall S, Hankins M, Marteau TM. Evaluating three theory-based interventions to increase physicians' recommendations of smoking cessation services. Health Psychol. 2009;28(2):174-182.

35. Moyer CA, Dryden T, Shipwright S. Directions and dilemmas in massage therapy research: a workshop report from the 2009 North American Research Conference on Complementary and Integrative Medicine. Int $J$ Ther Massage Bodywork. 2009;2(2):15-27.

36. Gryll SL, Katahn M. Situational factors contributing to the placebo effect. Psychopharmacology. 1978;57:253-261.

37. Kaptchuk TJ. The placebo effect in alternative medicine: can the performance of a healing ritual have clinical significance? Ann Intern Med. 2002;136(1):817-825.

38. Iowa Bureau of Professional Licensure. Iowa Board of Massage Therapy. 2008. Retrieved from http://www.idph.state.ia.us/ licensure/MassageTherapy.aspx

39. Downey MA, Tyree PT, Lafferty WE. Preventive screening of women who use complementary and alternative medicine providers. J Womens Health. 2009;18(8):1133-1143.

40. Burke A, Ginzburg K, Collie K, Trachtenberg D, Muhammad M. Exploring the role of complementary and alternative medicine in public health practice and training. J Altern Complement Med. 2005;11(5):931-936. 
BOULANGER: PERSONAL CHARACTERISTICS AND BEHAVIORS

41. National Center for Complementary and Alternative Medicine. NCCAM Third Strategic Plan 2011-2015: Exploring the Science of Complementary and Alternative Medicine. NCCAM; 2011. Retrieved from http://nccam.nih.gov/about/plans/2011/

42. Thompson D. The 2010 highlighting massage therapy in complementary and integrative medicine research conference. Int J Ther Massage Bodywork. 2009;2(4):1-2.
Corresponding author: Karen T. Boulanger, $\mathrm{PhD}$, CMT, 1167 Brace Ave., San Jose, CA 95125, USA E-mail: drkarenboulanger@gmail.com 